\title{
Quality and payment: the U.S. experience of typing inpatient and outpatient casemix payments to quality measures and reporting JJ Shah
}

\author{
Address: Nimitt Consulting Inc., Washington, DC, USA \\ from 25th Patient Classification Systems International (PCSI) Working Conference \\ Fukuoka, Japan. II-I4 November 2009 \\ Published: 5 November 2009 \\ BMC Health Services Research 2009, 9(Suppl I):A19 doi:I0.1186/1472-6963-9-SI-AI9
}

This abstract is available from: http://www.biomedcentral.com/I472-6963/9/SI/AI9

(C) 2009 Shah; licensee BioMed Central Ltd.

\section{Introduction}

Over the past four to five years, the focus in casemix-based payment systems in the United States has shifted more and more towards "value-based-purchasing" and "payfor-performance" measures. The reporting of pre-set quality indicators is now fundamentally in place for both the inpatient prospective-payment system, based on Medicare-Severity Diagnosis Related Groups (MS-DRGs), and, more recently, the outpatient prospective-payment system, based on Ambulatory Payment Classifications (APCs).

For hospitals to receive their full casemix MS-DRG or APC payment, whether for inpatient services or outpatient services, all required quality indicators must be reported. Reporting pre-determined quality indicators is important for data collection and monitoring, but the simple act of reporting data does not, and should not, be used as a proxy to talk about the delivery of "high-quality" healthcare services. In fact, critics in the U.S. consider the current "pay-for-performance" system simply a "pay-for-reporting" system which does little to measure true quality, or the lack of it.

Additional quality-of-care concepts have been introduced more recently. These focus on the reporting of specific diagnoses that may influence final DRG assignment and, thus, final payment in the inpatient setting. These concepts focus on whether reported diagnoses were "Present on Admission" (POA), or whether they were "Hospital Acquired Conditions" (HACs) that surfaced during the patient's hospitalization.

Examining such data begins to tell a different story about the patient's disease state upon arrival to the hospital versus conditions, often considered preventable, that might have occurred during the stay. The practice of flagging diagnoses that are POA, versus those that are HACs, is one method the U.S. Medicare program uses to provide an incentive to hospitals to offer high-quality treatment while a patient is in their care.

If certain preventable conditions, including Never Events, occur during the patient's stay, then Medicare believes that these secondary diagnoses should not influence grouping, nor the final MS-DRG payment calculation. This link between the reporting of specific data, the assumption made about the quality-of-care rendered, and the final impact on payment is quite new, and to some extent controversial. It will be reviewed during this session.

\section{Methods}

This session will provide a review of the required inpatient and outpatient quality indicators that hospitals, under the Medicare program, must report in order to receive their full casemix payment. In addition, it will cover current requirements related to flagging certain diagnoses as POA, versus those that are considered HACs, and Never Events, as defined by Medicare. Finally, this session will provide a preview of Medicare's future plans related to measuring quality and typing it to payment.

\section{Results}

Much of the discussion focusing on quality and casemix has centered on reducing payments, rather than offering incentives, or extra payment, for hospitals that are truly innovative in their approach to offering high levels of patient safety, quality and access. Creating incentives that promote the delivery of high-quality healthcare is different from implementing mechanisms that withhold pay- 
ment from hospitals deemed to provide "poor-quality" care.

Understanding this nuance is critical to creating the "right" set of incentives for both efficiency and quality. Whether this can be done effectively by reducing, or withholding, casemix payment to hospitals that fail to report quality indicators, or that fail to provide quality healthcare (as defined by the list of HACs and Never Events), remains to be seen.

\section{Conclusion}

Measuring quality-of-care has always been difficult, and the fact that there is no one "right" answer complicates the discussion. Many studies have shown that neither higher costs, nor greater spending, nor higher utilization is a guarantee for high quality-of-care. In many cases, quite the opposite has been found. Therefore, a discussion about quality-of-care can begin with the reporting of certain data elements, and through the creation of certain incentives and disincentives related to payment.

But this is only the beginning of the quality, cost and payment debate, and we still have a long way to go. The use of quality concepts, insofar as they influence hospital payments, is still relatively new and somewhat controversial. However, it is in place in the United States.

Creating efficiency incentives for hospitals through the use of casemix-based payment systems must be carefully balanced along with ensuring patient access and safety, and providing high-quality healthcare services. This session aims to provide attendees with information about the U.S. experience, and the conclusions that can be drawn from it at present.

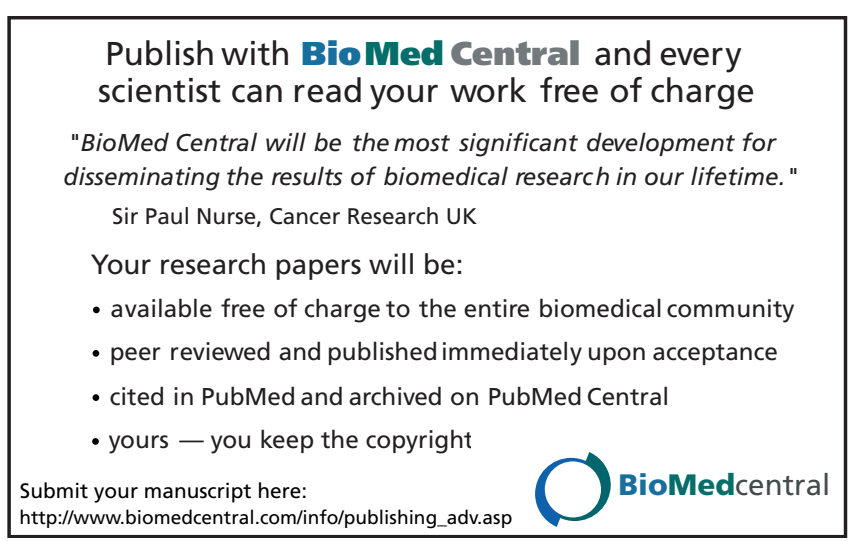

Page 2 of 2

(page number not for citation purposes) 